\title{
Geographic Information and Geo-visualisation in support of Disaster Resilience
}

\author{
Edward Kurwakumire $^{\mathrm{a}, *}$, Paul Muchechetere ${ }^{\mathrm{b}}$, Shelter Kuzhazha ${ }^{\mathrm{c}}$, Guy Blachard Ikokou ${ }^{\mathrm{a}}$ \\ ${ }^{a}$ Tshwane University of Technology, Geomatics Department, South Africa, KurwakumireE@tut.ac.za, IkokouGB@tut.ac.za \\ ${ }^{b}$ Paul Muchechetere, Midlands State University, Surveying and Geomatics Department, Zimbabwe, muchecheterep@staff.msu.ac.zw \\ ${ }^{c}$ Shelter Kuzhazha, Monash University, Department of Geography and Environmental Science, South Africa, \\ shelter.kuzhazha@monash.edu \\ * Corresponding author
}

\begin{abstract}
Society continues to become more spatially enabled as spatial data becomes increasingly available and accessible. This is partly due to democratisation of data achieved through open access of framework data sets. On the other hand, mobile devices such as smartphones have become more accessible, giving the public access to applications that use spatial data. This has tremendously increased the consumption of spatial data at the level of the general public. Spatial data has a history in planning and decision making as detailed in literature on promises and benefits of geographic information. We extend these promises to sustainability and disaster resilience. It is our belief that geographic information (GI) and geographic information infrastructures (GIIs) contribute positively towards the achievement of sustainability in cities and nations and in disaster resilience. This study carries out a review of geovisualisation and GI applications in order to determine their suitability and impact in disaster resilience. Real-time GI are significant for cities to ensure sustainability and to increase disaster preparedness. Geographic information infrastructures need to be integrated with BIG data systems to ensure that local government agencies have timely access to real time geographic information so that decisions on sustainability and disaster resilience can be effectively done.
\end{abstract}

Keywords: Geographic Information, Geo-visualisation, Resilience, Disaster Resilience

\section{Introduction}

The world today is increasingly facing challenges of natural disasters which are occurring with both increased frequency and intensity. As a result, the disaster risk in terms of infrastructure damaged and loss of life by people and animals, damage to ecosystems and environmental degradation has also increased. The natural disasters include floods, hurricanes and drought and these are highly correlated with climate change. Countries with coastal areas are at even higher risks as the oceans are often the source of hurricanes and tornadoes. This increasing frequency of natural disasters demands cities and nations to be better prepared in order to cope with the risk of natural disasters. This requires the use of early warning and disaster management systems which use real time geographic information as a central component for decision making. Cities and nations need systems that are resilient in order to cope with natural disasters. Resilience entails the ability of systems to maintain a state of equilibrium after experiencing the impacts of external shocks (Adger et al., 2005). Within resilience is a capacity to regenerate and adapt in order to reclaim the state of equilibrium. There are two major hypotheses in this study: (1) Geographic information positively influences sustainability of cities and nations and (2) Geographic information improves the effectiveness of disaster resilience systems. This study is based on a systematic review of literature from the fields of resilience, sustainability and geographic information infrastructures.

Resilience has been widely applied in the context of socio-ecological systems (SES) as evident from literature by (Adger et al., 2005; Folke et al., 2004; Walker et al., 2002). Social-ecological systems are complex adaptive systems and their management cannot solely rely on probabilistic measures of predicting the occurrences of external shocks such as climate change and floods. In order to achieve sustainability of a social-ecological system managers, need to be part of this socially constructed system (Walker et al., 2002). This study extends the resilience concept to disaster management. The terms socio-ecological systems and social-ecological systems are used interchangeably in this paper.

\section{Related Work}

\subsection{Resilience}

Resilient systems are tailor-made with "mechanisms for living with, and learning from, change and unexpected shocks" according to (Adger et al., 2005). Resilience is the ability for a system to maintain its functionality when it has been disturbed by external shocks that significantly changes its structure and functionality. This is achieved through renewal or reorganisation of elements or 
Informed disaster management should be complemented by governance systems at different levels covering different aspects of resilience in order for cities to adapt and cope with uncertainty and surprise of natural disasters (Adger et al., 2005).

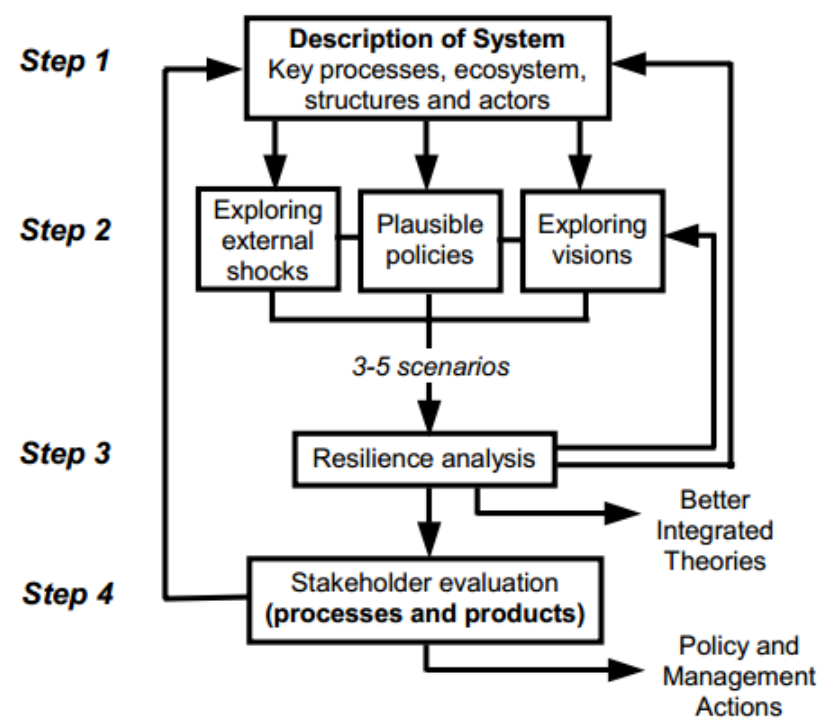

Figure 1. Framework for analysis of resilience in social-ecological systems (Walker et al., 2002).

Walker et al. (2002) presents a framework for analysis of resilience (see figure 1). This framework recognises the integration of technology, people and processes related to ecological systems in order to design scenarios and policies to improve disaster resilience.

\subsection{Geographic Information and Geo-visualisation}

Data is necessary in evidence based engagements together with all stakeholders, to influence policy, and controlling of negotiations in governance frameworks (Certomà et al., 2017). For humans, thinking and knowledge building is enhanced more by a visual context (through images and pictures) than textual and numerical contexts (Kwan, 2004). There are many forms of data visualisation in semantic and temporal dimensions, principally falling within scientific and information visualisation (Marzouki et al., 2017). If data has a combination of spatial, semantic and temporal dimensions it is referred to as geographical data/information, and termed geospatial data (Marzouki et al., 2017). Visualisation of such data becomes special, and becomes more than scientific and information visualisation. The generic term for such visualisation is termed geo-visualisation. In its entirety geo-visualisation, combines scientific visualisation, information visualisation, cartography, geographical information systems (GIS), exploratory data analysis and many more to seek alternative ways to explore, analyse, synthesise and represent geographic data/information (Nöllenburg, 2007). cartographic principles, but with technology advancement, the internet, networking platforms, big data and rise of neo-geography, alternative ways to represent geographic data/information emerged through geovisualisation. Geo-visualisations presents digital and modern ways to the representation of geospatial data other than technically connoted and regulated ways as sought by cartographic principles. In this case geovisualisations are more than just map, where maps had been the traditional representation of geospatial data (Keim, 2005). Geo-visualisations have been driven through geographical information systems (GIS), cartographic platforms, digital globes, virtual simulation environments, building information models, game platforms and other environments (Pettit et al., 2012).

\subsection{Geographic Information Infrastructures}

Geographic Information Infrastructures (GII) comprises of software, hardware and data used to store manipulate and analyse spatial data that can be visualized on a map. These properties make GII a key tool for disaster relief and management. By displaying a river that regularly floods on a GII, it is possible to assess the risks by displaying all the assets at certain spatial location from the river. The statistics of the affected population affected by the flood can also be assessed by adding population data to the GII map and adding the road network to the data would provide evacuation routes (Rurup, 2017). Disaster management can be defined as an applied science which seeks by systematic observations, an analysis of disasters in order to improve measures relating to prevention and preparedness, emergency response and recovery (Abella, 2002). Through knowing the temporal dimension of the disasters, disaster management has been organising in four phases of the disaster management cycle: Prevention, Preparedness, Response and Recovery.

Any type of disaster as well as their spatio-temporal magnitude can be spatially represented in a geographic information infrastructure and this can produce a historical occurrence of the disaster while enabling better preparation for future disasters in order to reduce the risks on physical infrastructure and people. Regardless of the well-documented benefits, there is still need for investigation in terms of further utilising GII for disaster management. In addition, the scope, scale, and intensity of disaster impacts continue to increase. Disasters now affect larger numbers of populations in big cities as observed in Burkina Fasso in 2009 and 2010 where many lives were lost due to poor disaster management and lack of technology. GII for disaster management can improve the disaster management practice through improved coordination and sharing of geographic information, geovisualisation and decision-making resources (Tomaszewsk, 2015).

Traditionally geospatial data visualisation was based on 


\begin{tabular}{|c|c|c|c|}
\hline $\begin{array}{l}\text { Potential } \\
\text { visualisation } \\
\text { Application }\end{array}$ & Source & $\begin{array}{l}\text { Possible Disaster } \quad \text { Management } \\
\text { Goal }\end{array}$ & $\begin{array}{l}\text { Potential Applicability } \\
\text { to SES Framework }\end{array}$ \\
\hline \multirow{7}{*}{ Susceptibility Modelling } & \multirow{7}{*}{$\begin{array}{l}\text { (Cummings et al., } \\
\text { 2012); (Kugler, } \\
\text { 2012); (Regmi et } \\
\text { al., 2014); (Umar et } \\
\text { al., 2014) }\end{array}$} & Crisis Preparedness & \\
\hline & & Crisis Response & \\
\hline & & Disaster Prediction & \\
\hline & & Preventative Monitoring & \\
\hline & & Evacuation Planning & \\
\hline & & Early Warning & \\
\hline & & Disaster Mitigation Planning & Step 3 and Step 4 \\
\hline \multirow{8}{*}{ Severity Modelling } & \multirow{8}{*}{$\begin{array}{l}\text { (Kim and Hastak, } \\
\text { 2018); (Kugler, } \\
2012) ; \quad(\text { Lu et al., } \\
2018) ; \\
\text { Albuquerque et al., } \\
2015)\end{array}$} & Crisis Response & \multirow[b]{8}{*}{ Step 3 and Step 4} \\
\hline & & Disaster Assessment & \\
\hline & & Intervention Planning & \\
\hline & & $\begin{array}{l}\text { Post Disaster Reconstruction } \\
\text { Planning }\end{array}$ & \\
\hline & & Evacuation Planning & \\
\hline & & Emergency information Propagation & \\
\hline & & Preventative Monitoring & \\
\hline & & Vulnerability \& Capacity Planning & \\
\hline \multirow{6}{*}{ Inventory Mapping } & \multirow{6}{*}{$\begin{array}{l}\text { (de Albuquerque et } \\
\text { al., 2015); (IFCR, } \\
\text { 2007) }\end{array}$} & Preventative Monitoring & \multirow[b]{6}{*}{ Step 1 and Step 2} \\
\hline & & Disaster Prediction & \\
\hline & & Disaster Assessment & \\
\hline & & Emergency Contingency Plans & \\
\hline & & Intervention Planning & \\
\hline & & Disaster Mitigation Planning & \\
\hline \multirow{10}{*}{ Risk Modelling } & \multirow{10}{*}{ 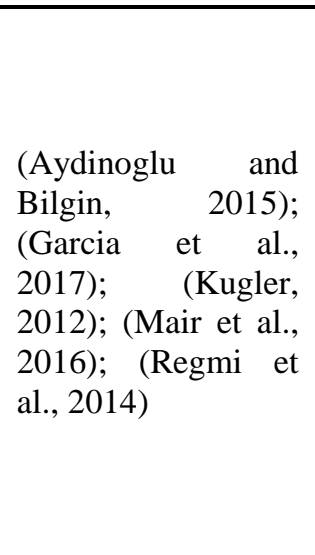 } & Preventive Monitoring & \multirow{10}{*}{$\begin{array}{l}\text { Step 2, Step } 3 \text { and Step } \\
4\end{array}$} \\
\hline & & Emergency Contingency Plans & \\
\hline & & Disaster Prediction & \\
\hline & & Crisis Preparedness & \\
\hline & & Crisis Response & \\
\hline & & Evacuation Planning & \\
\hline & & Disaster Mitigation Planning & \\
\hline & & Disaster Assessment & \\
\hline & & Intervention Planning & \\
\hline & & Vulnerability \& Capacity Planning & \\
\hline
\end{tabular}




\begin{tabular}{|c|c|c|c|}
\hline \multirow{6}{*}{ Predictive Modelling } & \multirow{6}{*}{$\begin{array}{l}\text { (Cummings et al., } \\
\text { 2012); (Di Stefano } \\
\text { et al., 2017); (Mair } \\
\text { et al., 2016); } \\
\text { (Regmi et al., 2014) }\end{array}$} & Crisis Response & \multirow[b]{6}{*}{ Step 2 and Step 4} \\
\hline & & Intervention Planning & \\
\hline & & Evacuation Planning & \\
\hline & & Preventative Monitoring & \\
\hline & & Disaster Prediction & \\
\hline & & Vulnerability \& Capacity Planning & \\
\hline \multirow{8}{*}{ Vulnerability Modelling } & \multirow{8}{*}{$\begin{array}{l}\text { (de Albuquerque et } \\
\text { al., 2015); (Kugler, } \\
\text { 2012); (Regmi et } \\
\text { al., 2014); (Umar et } \\
\text { al. 2014) }\end{array}$} & Crisis Preparedness & \multirow[b]{8}{*}{ Step 2 and Step 3} \\
\hline & & Crisis Response & \\
\hline & & Vulnerability \& Capacity Planning & \\
\hline & & Disaster Prediction & \\
\hline & & \begin{tabular}{|l|} 
Preventative Monitoring \\
\end{tabular} & \\
\hline & & Evacuation Planning & \\
\hline & & Early Warning & \\
\hline & & Disaster Mitigation Planning & \\
\hline \multirow{7}{*}{$\begin{array}{l}\text { Space Time Modelling } \\
\text { (Pre, During and Post } \\
\text { Disaster Modelling) }\end{array}$} & \multirow{7}{*}{$\begin{array}{l}\text { (Di Stefano et al., } \\
\text { 2017); (Kugler, } \\
\text { 2012) }\end{array}$} & Preventative Monitoring & \multirow{7}{*}{$\begin{array}{l}\text { Step 1, Step 2, Step 3, } \\
\text { and Step } 4\end{array}$} \\
\hline & & Post Disaster Construction & \\
\hline & & Disaster Mitigation & \\
\hline & & Evacuation Planning & \\
\hline & & Emergency Contingency Planning & \\
\hline & & Search and Rescue Operations & \\
\hline & & Preventative Monitoring & \\
\hline $\begin{array}{l}\text { Community Contingency } \\
\text { Modelling }\end{array}$ & $\begin{array}{l}\text { (Mair et al., 2016), } \\
\text { (de Albuquerque et } \\
\text { al., 2015) }\end{array}$ & Emergency Contingency Planning & Step 3 and Step 4 \\
\hline
\end{tabular}

Table 1: Review of Geo-visualisation for Disaster Management

\section{Methods}

The research takes a qualitative review within a rapid literature review framework to draw down the applicability of geographic information and geovisualisation in disaster management, with emphasis on resilience of a socio-ecological system (SES). Cities are viewed as socio-ecological systems in this study as they comprise social and ecological ecosystems together with the built environment which coexist. The research takes a twin review framework of: (1) application of geovisualisation in disaster management and (2) contextualising resilience within SES for disaster management. We recognise that this is still an ongoing research and that a systematic literature review is still required to better understand uses of particular geovisualisations tools or methods in contextualising resilience for managing particular disasters in particular
SESs. As such, this study sought for literature pertaining to resilience and disaster management as contextualised in SESs, then literature considering use of geovisualisation in disaster management. The articles reviewed included books, journal articles and conference publications with examples, cases and or empirical studies.

This was done following a stepwise approach to firstly gain a general understanding of how resilience can be described within SES for disaster management, then lastly to reveal application of geo-visualisations to disaster management. This was helpful in presenting a synthesis of how geo-visualisation can be useful to express different SES disaster management scenarios which can be coupled with resilience information for better management of disasters.

The rapid literature review was carried out in three major steps: Step 1- In order to review literature on disaster resilience, SES and disaster management a search for 
(policy documents) and peer reviewed articles through their titles and abstracts was conducted using key terms "disaster resilience" or "disaster management" and "socio ecological systems". The articles were searched in Web of Science (WoS) and Scopus databases. Only peerreviewed papers journals were retained. In WoS, papers were sorted according to the times cited and the five most cited papers that dealt with "disaster resilience" and/or "disaster management" and/or "socio ecological systems". In Scopus, papers were sorted by relevance and the five most relevant papers were also retained. Papers were selected through awarding three passes: a first pass on paper titles, then a second pass on paper abstracts, and finally a third pass through paper contents in order to select only relevant papers. Ten relevant papers were retained and analysed to offer a better understanding of disaster resilience, SES and disaster management. Step 2 - With regard to geo-visualisation, the review proceeded with searches from peer reviewed journals to seek for titles and abstracts that include the phrase (use cases of "geographic information" or "geo-visualisation" in "disaster resilience" or "disaster management" or "Socio Ecological Systems modelling"). The search sought for peer reviewed articles published in the Web of Science and Scopus databases. After filtering the sought titles and abstracts, the research followed up on the full bodies of the articles to seek explanations on the specificities on the use of geo-visualisation in disaster management. Step 3Synthesis of Geo-visualisation use case to model disaster scenarios at SES scales, and how resilience can then be sought in those SES for managing disasters. This resulted in table 1 which relates geo-visualisation applications to disaster management goals and the aspects from the SES framework from figure 1 , that are addressed.

The second phase of the methodology involved the adoption of the framework for managing any analysing resilience of socio-ecological systems presented in (Walker et al., 2002). For the purposes of this study, this framework is embedded on geographic information through layers of geo-visualisation at different scales, resolution and levels of complexity. The resilience framework is viewed as a component of the geographic information infrastructure as resilience processes are aligned to use GI and tools within the infrastructure. The framework in Walker et al. (2002) comprises four steps (see figure 1) with the social-ecological system stakeholders at the heart of each step.

\section{Resilience in Disaster Management}

It is seldom impossible to reduce the impact of external shocks as rapidly as systems change in order to maintain the state of equilibrium (Walker et al., 2002). The practicality of disaster resilience is difficult to achieve since it is impossible for societies to influence the occurrence and course of natural hazards that attack their social-ecological systems. Much can however be done by societies and resilience managers in mitigating risk upon the occurrence of natural disasters (Paton and Johnston, 2017).
While the goal of resilience management is to ensure that systems maintain states of equilibrium but refraining from moving into undesirable configurations where their functionality is disturbed, this is highly dependent on the adaptive capacity of the system. In the face of many uncertainties such as floods, tsunamis and droughts, it is imperative to determine and understand the components of the system that are in fact, resilient (Walker et al., 2002). Policies can then be generated to support resilience of these components. The overall administration and management of the disaster resilience system is in the custodians of stakeholders responsible for different components of the system who form the governance structure. To incorporate more learning, the system needs access to BIG data systems that provide real time geographic and disaster information and has access to data warehouses from all stakeholder organisations which means there must be interoperability between systems. The information within the BIG data systems needs to be stored in a format such that it is ready for use by different users meaning mapping and geo-visualisation standards are adhered to for easy communication of information and analysis for informed decision making. Meta data is key to the usability of geographic information as it details the characteristics relating to the quality of the data. Within disaster management and resilience, the time period for which data was captured is a highly determining factor on the appropriateness of data for decision making. For example, a satellite image of a veld fire taken 24 hours ago would not assist in determining the current direction of the fire in order to perform a rescue operation. However, that image can be used to assess the damage that had occurred due to the fire, in this case, the external shock, to the environment and infrastructure as of 24 hours from the current time period.

The management and governance of disaster resilience needs to be active and adaptive in order to maintain the equilibrium and functionality of systems (Folke et al., 2004). There should be a continuous feedback loop to incorporate learning from previous shocks in order to improve the management of disaster resilience.

Based on the framework depicted in figure 1, the first step is to explicitly define the city as a socio-ecological system in terms of scope, boundaries, objectives, processes and stakeholders involved. Secondly, there is need to detail the external shocks that this system can experience or is built to fight against as it is not possible to cover all shocks. The resilience management system may address floods, for example. For each shock identified, the disaster resilience management stakeholders develop policies for managing the risk resulting from each shock. The stakeholders develop scenarios using geographic information and geovisualisation tools within the geographic information infrastructure. 
Step 3 involves analysing these 'what if' scenarios to better define the policies set up in step 2 and set concrete visions for the disaster resilience management system. The final step involves stakeholder evaluation of the resistance framework based on post-disaster capability of systems to either remain functional or to return to their state of optimal functioning. The information from the evaluation is fed to step 1 to refine the description of the resilience system from the recommendations from learning and experiences from current and historical external shocks that have attacked the city.

\section{Geographic Information and Geo- visualisation in Disaster Management}

Within the realm of Geoinformation experts are land administration managers who manage the land resource. Good governance in land and disaster risk management should result in empowerment of vulnerable groups so that they are resilient to disaster risk. This empowerment of vulnerable groups particularly in rural and informal tenure areas transforms them into resilient communities, is a responsibility of land administrators (Unger et al., 2019). The land information collected by land administrators facilitates disaster risk planning and management.

Disaster management and learning about a community's coping capability, may allow to carry out these seven environmental modelling techniques among many (1) susceptibility modelling, (2) Severity Modelling, (3) Inventory Mapping, (4) Risk Modelling, (5) Predictive Modelling, (6) Vulnerability Modelling, (7) Space Time Modelling (Pre, During and Post Disaster Modelling), (8) Community Contingency Modelling (see table 1). This helps the community to understand the level of risk it will be in, and to reveal their susceptibility and vulnerability to a disaster and as such makes the community aware about their crisis/disaster preparedness, crisis/disaster response, preventative capability, usefulness of evacuation plans, disaster mitigation planning and other disaster management factors. These models help the community and other disaster managers to explore the phenomenon and eventually may be able to find answers that may help in controlling, mitigating and coping with the effects of the disaster. Through geo-visualisation high interactive capabilities, dynamism and exploratory capabilities may allow for "gazing into the future", which may be highly useful in understanding the community susceptibility and vulnerability to a disaster and eventually how that community might cope with that disaster.

As expressed by Çöltekin et al. (2017) it is usually a problem to identify the right geo-visualisation method for a particular task or purpose. Such difficulty is justified by Nollenberg (2007), when it is indicated that different types of geo-visualisations can be developed for a particular task, depending on the nature of collected data, the type of user and the medium in which the visualisation is presented. It is not imperative to restrict the user to a choice of geo-visualisation. In that case it may be prudent to point a user to capabilities of geovisualisations to help in exploring a certain phenomenon depending on a task. Geo-visualisations may offer numerous possibilities to understanding geographical phenomena, through phenomena exploration, analysis, revelation and communication. Hence the goals of geovisualisations are various, which this paper may not be able to exhaust. As presented by the map use cube (Kraak and MacEachren 1997; Nollenburg, 2007), geovisualisation serve many purposes, and their design give the level of possibility in which geo-visualisations can be useful, usable or applicable. As contended by Nollenberg (2007) geo-visualisation goals ranges from exploration, to presentation (with the four mentioned goals being Exploration; Analysis; Synthesis and Presentation). All these gives possibilities to how geo-visualisation are useful and usable to disaster management when considering a community's resilience to that phenomena.

Resilience is place or space specific with places or spaces synonymous to socio-ecological systems (SES). Thus for geospatial experts and disaster resilience managers to model resilience they need to understand place or space facts which are synonymous to ecological facts. These facts are spatially related as they differ from area to area depending on location. These facts are contextualised through SES which are the units to be managed with the geospatial facts being the ecological data of the SES. A challenge however exists in visualising this facts and contexts which can be solved through geo-visualisations or maps. From this arrives a need to use geo-visualisation to contextualise SES, then to understand resilience at SES level for better management of disasters.

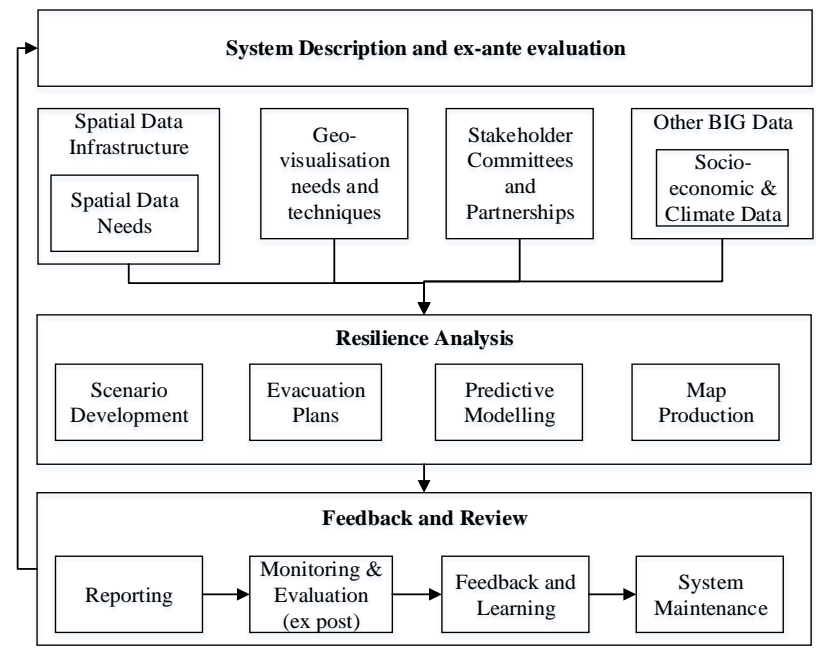

Figure 2. Spatially Enabled Resilience Framework.

Based on the SES framework by (Walker et al., 2002) and the importance of spatial data for disaster resilience, a spatially enabled disaster resilience framework is presented (see figure 2). The system design phase takes into account the spatial data requirements and geovisualisation techniques required to present the data to different stakeholders. Spatial data is acquired from the spatial data infrastructure and additional data from BIG 
data systems maintained by government. Resilience analysis involves the development of what if analyses, time series analysis and production of map products to present the scenarios. To improve the system and ensure there is continuous learning the last phase is feedback and review in which an ex post evaluation of the system is done.

\section{Conclusions}

Resilience provides an interesting viewpoint towards improving disaster management from a theoretical point of view. Literature presents resilience as a logical concept for cities to be more prepared for disaster risk. There is however, need to delineate where the practical application boundaries commence and end including the fuzzy areas. Unlike a computer system which can survive from a software crash or virus attack, actual disaster risks cannot in principle be reversed. Thus not all systems can return to their initial state of equilibrium. Disaster resilient systems can limit the risk and ensure resources are available for post disaster recovery. A resilient disaster management system is not an end in itself, but rather a means to an end. The end is described as the capability of the city to restore affected components and systems including infrastructure after the occurrence of a disaster. Resilient systems are expected to learn and adapt, so that they become complex adaptive systems. By learning from historical natural disasters, cities are better prepared can focus of developing infrastructure that can withstand the impact of natural disasters and hence protect the public.

Geographic information plays an important role in scenario development, disaster modelling, post disaster analysis and in the execution of search and rescue operations. Through geo-visualisation, different disaster scenarios can be viewed graphically and field teams can access this information through mobile devices to assist in search and rescue operations. Geographic information, geo-visualisation and the related geographic information infrastructures assist in collecting the data, processing, performing modelling functions, visualising the data and information and in aiding disaster management and resilience decision making. While geographic information can greatly aid disaster management, achieving disaster resilience still requires further investigation. People or live-ware still remain integral to any resilience framework or system as such systems cannot seemingly operate autonomously. People remain the ultimate decision makers based on policies embedded in the resilience framework and scenarios provided by the geographical information based decision support tool. Disaster preparedness, however benefits from the continuous collection and analysis of spatially enabled disaster information and improving disaster prediction algorithms and models based on historical data and new trends. This results in well-defined early warning systems and post disaster management systems that enable cities to return to their states of equilibrium in the shortest possible time.

\section{References}

Abella, E.C. (2002). "GII for Natural Disaster Management", III Congreso Internacional GEOMATICA 2002. 18-23 Febrero del 2002, Palacio de las Convenciones, La Habana, Cuba.

Adger, W.N., Hughes, T.P., Folke, C., Carpenter, S.R., and Rockström, J. (2005). Social-ecological resilience to coastal disasters. Science. 309(5737), pp. 1036-1039.

Aydinoglu, A.C. and Bilgin, M.S. (2015). Developing an open geographic data model and analysis tools for disaster management: landslide case. Natural Hazards and Earth System Sciences, 15(2), pp. 335-347.

Burns, R. (2015). Rethinking big data in digital humanitarianism: Practices, epistemologies, and social relations. GeoJournal, 80, pp. 477-490.

Certomà, C., Dyer, M., Pocatilu, L. and Rizzi, F. eds. (2017). Citizen Empowerment and Innovation in the Data-Rich City. Springer.

Çöltekin, A., Bleisch, S., Andrienko, G. and Dykes, J. (2017). Persistent challenges in geovisualisation-a community perspective. International Journal of Cartography, 3(sup1), pp. 115-139.

Cummings, C.A., Todhunter, P.E. and Rundquist, B.C. (2012). Using the Hazus-MH flood model to evaluate community relocation as a flood mitigation response to terminal lake flooding: The case of Minnewaukan, North Dakota, USA. Applied Geography, 32(2), pp. 889-895.

De Albuquerque, J.P., Herfort, B., Brenning, A. and Zipf, A. (2015). A geographic approach for combining social media and authoritative data towards identifying useful information for disaster management. International Journal of Geographical Information Science, 29(4), pp. 667-689.

Di Stefano, R., Tinti, E., Scognamiglio, L., Michele, M. (2017). The 2016 Central Italy Seismic Sequence: A First Look at the Mainshocks, Aftershocks, and Source Models. Seismological Research Letters. 88(3), pp. 757771.

Folke, C., Carpenter, S., Walker, B., Scheffer, M., Elmqvist, T., Gunderson, L. and Holling, C.S. (2004). Regime shifts, resilience, and biodiversity in ecosystem management. Annu. Rev. Ecol. Evol. Syst., 35, pp. 557581.

Garcia, L.C., Ribeiro, D.B., de Oliveira Roque, F., Ochoa-Quintero, J.M. and Laurance, W.F. (2017). Brazil's worst mining disaster: corporations must be compelled to pay the actual environmental costs. Ecological applications, 27(1), pp. 5-9.

Hirabayashi, Y., Mahendran, R., Koirala, S., Konoshima, L., Yamazaki, D., Watanabe, S., Kim, H., and Kanae, S. (2013). Global flood risk under climate change. Nature Clim. Chang. 3, pp. 816-821.

IFRC. (2007). VCA Toolbox with Reference Sheets; International Federation of Red Cross and Red Crescent: Geneva, Switzerland. 
Keim, D.A. (2005). Information visualisation: Scope, techniques and opportunities for geovisualisation. In Exploring geovisualisation, pp. 21-52.

Kim, J. and Hastak, M. (2018). Social network analysis: Characteristics of online social networks after a disaster. International Journal of Information Management, 38(1), pp.86-96.

Kraak, M.J. and Ormeling, F.J. (1996), Cartography: visualisation of spatial data. Harlow, Essex: Addison, Wesley Longman Ltd.

Kugler, Z. (2012). Remote sensing for natural hazard mitigation and climate change impact assessment. Quarterly Journal of the Hungarian Meteorological Service, 116(1), pp. 21-38.

Kwan, M.P. and Lee, J. (2004). Geovisualisation of human activity patterns using 3D GIS: a timegeographic approach. Spatially integrated social science, 27.

Lu, Y., Xu, D., Wang, Q. and Xu, J. (2018). Multistakeholder collaboration in community post-disaster reconstruction: case study from the Longmen Shan Fault area in China. Environmental Hazards, 17(2), pp. 85-106.

Mair, J., Ritchie, B.W. and Walters, G. (2016). Towards a research agenda for post-disaster and post-crisis recovery strategies for tourist destinations: A narrative review. Current Issues in Tourism, 19(1), pp. 1-26.

Marzouki, A., Lafrance, F., Daniel, S. and Mellouli, S. (2017). The relevance of geovisualisation in Citizen Participation processes. In Proceedings of the 18th Annual International Conference on Digital Government Research, pp. 397-406, ACM. June 2017.

Morrow, B.H. (1999). Identifying and Mapping Community Vulnerability. Disasters. 23(1), pp. 1-18.

Nöllenburg, M. (2007). Geographic visualisation. In Human-centered visualisation environments (pp. 257294). Springer, Berlin, Heidelberg.

Paton, D. and Johnston, D. (2017). Disaster resilience: an integrated approach. $2^{\text {nd }}$ Edition, Charles C Thomas Publisher Ltd.

Pettit, C., Widjaja, I., Russo, P., Sinnott, R., Stimson, R. and Tomko, M. (2012). Visualisation support for exploring urban space and place. International Society for Photogrammetry and Remote Sensing.

Philip, J.W., Brenden, J., Frederiek Sperna, W., Arno, B., van Rens, B., Marc, F.P.B., Willem, L., and Hessel, C.W. (2013). Assessing flood risk at the global scale: Model setup, results, and sensitivity. Environ. Res. Lett. 8.

Regmi, A.D., Devkota, K.C., Yoshida, K., Pradhan, B., Pourghasemi, H.R., Kumamoto, T. and Akgun, A. (2014). Application of frequency ratio, statistical index, and weights-of-evidence models and their comparison in landslide susceptibility mapping in Central Nepal Himalaya. Arabian Journal of Geosciences, 7(2), pp. 725-742.
Rurup A. (2017). Strengthening Capacities for the use of GII in disaster risk reduction. Masters Thesis, Lund University, Sweden.

Tomaszewski, B. (2015). Geographic Information Systems (GII) for Disaster Management. Taylor and Francis.

Umar, Z., Pradhan, B., Ahmad, A., Jebur, M.N. and Tehrany, M.S. (2014). Earthquake induced landslide susceptibility mapping using an integrated ensemble frequency ratio and logistic regression models in West Sumatera Province, Indonesia. Catena, 118, pp. 124135 .

Unger, E.M., Zevenbergen, J., Bennett, R. and Lemmen, C. (2019). Application of LADM for disaster prone areas and communities. Land use policy, 80, pp. 118126.

Van Der Knijff, J.M., Younis, J., De Roo, A.P.J. (2010). Lisflood: A GIS-based distributed model for river basin scale water balance and flood simulation. International Journal of Geographic Information Science. 24, pp. 189-212.

Walker, B., Carpenter, S., Anderies, J., Abel, N., Cumming, G., Janssen, M., Lebel, L., Norberg, J., Peterson, G.D. and Pritchard, R. (2002). Resilience management in social-ecological systems: a working hypothesis for a participatory approach. Conservation ecology, 6(1). 